\title{
User preferences for web design compared: Are age-specific interface guidelines necessary?
}

\author{
Karin Slegers MSc \\ Institute of Brain and Behaviour, Faculty of Psychology \\ Martin P. J. van Boxtel PhD \\ Jelle Jolles PhD \\ Institute of Brain and Behaviour, Faculty of Psychology \& Faculty of Medicine \\ Universiteit Maastricht, The Netherlands \\ E: info-np@np.unimaas.nl
}

\begin{abstract}
K. Slegers, M.P.J. van Boxtel, J. Jolles, User preferences for web design compared: Are age-specific interface guidelines necessary? Gerontechnology 2005; 4(3):153-165. Many guidelines exist for the design of user interfaces for older users that are primarily based on age-related limitations in perceptual, motor, and cognitive abilities. This study was designed to compare the preferences of older and younger users on several characteristics of web design and to compare these preferences with existing guidelines. Results showed that the web design preferences of older and younger users appear to be very similar, which supports the 'universal design' approach. User preferences largely corresponded to those incorporated into guidelines. However, the fact that some discrepancies between guidelines and preferences were found indicates that, in addition to user capabilities, user preferences should also be taken into account in web interface design.
\end{abstract}

Keywords: aging, web design, guidelines, preferences

The internet has a lot to offer older adults in terms of autonomy support and quality of life improvement. First, it helps individuals to keep in touch with the outside world and to maintain social contacts, which is particularly essential for individuals with physical impairments ${ }^{1-3}$. Indeed, the use of internet services has been shown to increase the perception of social support ${ }^{4,5}$. Second, it provides users with access to relevant information, for instance, about health issues $^{3,5}$ and hobbies'. Third, by providing services like home shopping and home banking, the internet may facilitate instrumental activities of daily living, which are important for autonomous functioning ${ }^{6}$. Finally, there is evidence that internet use may have psychological benefits, such as increased well-being and sense of control ${ }^{4}$.

Apart from these obvious advantages, in the past decade the ability to use information technology has become increasingly important in our daily lives. For instance, collecting money from a bank account has become virtually impossible in the Netherlands without using a cash machine as most banks are phasing out desk transactions. Furthermore, many computer-based assistive devices have become available which can support older adults in their daily routines, for instance, microwave ovens to prepare ready-made meals, computer systems providing reminders of medical schedules, etc.

A number of studies have drawn attention to the fact that older adults seem to experience problems when dealing with information technology or internet services, such as web surfing and e-mail. Older adults need more time, are more error-prone, and need more steps to 
reach their goals ${ }^{7-12}$. Yet despite these encountered difficulties, older adults are able and willing to learn such new skills and appear to enjoy it as well ${ }^{1,3,13}$.

In order to improve internet 'performance' of older individuals, it is important to take into account age-related limitations when designing computer interfaces. Nowadays, the development of adequate guidelines for the design of computer interfaces and websites for older adults has become an important research area $^{14,15}$.

As a result of this, guidelines have become available for the design of user interfaces and, more specifically, web interfaces $^{16,17}$. More recently, attention has been directed to the development of guidelines that specifically focus on interface design for older adults ${ }^{6,14,18-20}$. These guidelines are mainly based on age-related changes in perceptual, motor, and cognitive abilities that might cause older adults to experience more difficulties in using computers and the internet. For instance, visual acuity and contrast sensitivity diminish with age, which causes a decreased ability to discern small details and colour hues of visual objects. Aiming movements become less accurate with age, which can interfere with mouse pointer movement towards targets such as hyperlinks or buttons. Furthermore, cognitive functions such as working memory and spatial memory are recruited in order to remember previously visited web pages and to keep track of the virtual orientation in cyberspace. Behavioural planning is needed to develop efficient strategies and attention resources are required in order to extract relevant information from the screen. As these cognitive functions tend to decline with age ${ }^{21,22}$, there is a strong point for taking potential restrictions in these abilities of older users into account.
Design guidelines based on abilities that are susceptible to age-related decline indeed generally focus on age-related functional limitations, not on user preference. It seems reasonable to suppose that, apart from esthetical considerations, a user's preference is also based on a user's functional capacity. For example, a user with poor eyesight may be more proficient if a website has large letters and graphics and may for this reason have a tendency to prefer this type of website. Research on the relationship between performance and preferences is scarce. However, there is empirical evidence that people's design preferences do not always match designs that are predicted to be optimally usable based on their capabilities. For instance, a study by Bernard, Liao and Mills ${ }^{23}$ showed that for online reading purposes, a 14-point serif font supported faster reading, while older adults in the same study (62 - 83 years of age) actually preferred a sans serif font. Thus, despite the fact that a user's preferences probably resemble the user's abilities, it is important to consider user's preferences when developing interface guidelines - a website that is designed to meet its users' abilities but not their preferences may be less attractive to (and thereby less effective for) its intended users.

The present study set out to investigate web design preferences in older and younger adults by strictly manipulating a series of design aspects within a context of a fixed interface design. We were primarily interested in people's first impression of usability of a website, not in the actual usability of that website based on performance measures. Therefore, we asked older and younger internet users to judge the usability of several websites on face value. Given that older users experience more difficulties when navigating websites than do younger users due to age-related limita- 
tions, it was expected that older users prefer websites that take such limitations into account. Younger adults have fewer physical and cognitive limitations than older adults, or may have different opinions on design aesthetics, and may therefore have different preferences. Still, the approach of universal design ${ }^{24}$ assumes that the usability of products, including user interfaces, is optimal when these products have been designed for people of all ages and abilities. Thus, from this perspective, guidelines that are designed for older adults should also be appropriate for younger adults, which could imply similar preferences for the design of websites in different age groups.

Our second question concerned whether user preferences are consistent with existing guidelines. Table 1 provides an overview of a number of guidelines, derived from the literature, formulated for older interface users. These guidelines were mainly based on observed age-related changes in visual, perceptual, cognitive and motor skills. Unfortunately, there has been very little research into the relationship between these guidelines and actual performance of older computer users, and therefore, only general guidelines are available at the present time ${ }^{6}$. The guidelines cover aspects of interface design that were also included in the present study. We assumed that a user's preferences match his/her abilities and thus are older users' preferences compatible with these guidelines.

\section{Methods \\ Participants}

Participants in this study were recruited at the public library of the city of Maastricht, the Netherlands. Visitors of the library were randomly approached and asked to take part in the study. Participants were required to have some internet experience. 107 individuals, aged 19 to 78 years, agreed to participate. The participants were divided into four age groups: (i) 19-34, (ii) 35-49, (iii) 5064 and (iv) 65-80 (Table 2).

\section{Measurements}

User preferences were tested in two ways: using screen examples and by giving generic examples of web designs in questionnaire format. As preferences to

Table 1. Interface design guidelines for older adults used in this study

\begin{tabular}{|c|c|}
\hline Guidelines & Remark \\
\hline \multirow[t]{3}{*}{ Text } & Avoid using small character sizes $6,14,18,19,20$ \\
\hline & Use sans serif fonts ${ }^{14,19,20}$ \\
\hline & Use left justified text; avoid centered or full justification ${ }^{14,19}$ \\
\hline \multirow{2}{*}{ Visibility } & Maximize contrast between characters and background $6,4,18,19,20$ \\
\hline & Place text on unpatterned background ${ }^{14,18,19}$ \\
\hline \multirow{7}{*}{$\begin{array}{l}\text { Visual } \\
\text { clutter }\end{array}$} & Apply principles of perceptual organization (e.g. grouping) $)^{6,20}$ \\
\hline & Present information on consistent locations ${ }^{6,19}$ \\
\hline & Use white space actively ${ }^{14,19}$ \\
\hline & Use headings or subheadings ${ }^{19}$ \\
\hline & Avoid flashing/blinking text ${ }^{19}$ \\
\hline & Clearly label each section ${ }^{14}$ \\
\hline & Avoid using elements that compete for attention ${ }^{20}$ \\
\hline \multirow[t]{5}{*}{ Navigation } & Minimize number of hyperlinks in a line of text ${ }^{19}$ \\
\hline & Use buttons with symbols and text ${ }^{19}$ \\
\hline & Provide visual feedback on selection ${ }^{19}$ \\
\hline & Use icons as hyperlinks rather than underlined text ${ }^{14}$ \\
\hline & Use placement conventions common to other sites ${ }^{18}$ \\
\hline \multirow[t]{4}{*}{ Orientation } & Avoid multi-column format or frames ${ }^{19}$ \\
\hline & Minimize demands on spatial and working memory ${ }^{6,14,19}$ \\
\hline & Avoid walking menus ${ }^{14}$ \\
\hline & Provide visual cues for environmental support ${ }^{14}$ \\
\hline
\end{tabular}


more general features of web design, such as the use of roll over effects or frames, do not depend on the context, these preferences were measured with broader questions. Also, design aspects that could not be altered from the original website, such as different types of orientation cues, were presented to the participants in the questionnaire. On screen, examples of existing websites were shown to the participants. Only websites were selected which aimed for a general public. Of each website, different versions were subsequently presented, in which one distinct design characteristic (for instance, font size, background contrast) was changed. The screen examples, which are discussed in more detail below, are available at http://www.pivo.unimaas.nl/docs/webdesign_PIVO_total_2509.ppt. These versions were presented on a standard notebook computer (Apple Macintosh iBook, screen resolution: 24 bit, $800 \times 600$ ), using standard presentation software (Microsoft PowerPoint). As was mentioned above, these guidelines were mostly formulated based on observed age-related decline and have not been empirically tested. Therefore, we could not rely on existing material to compare the guidelines with user preferences. Instead, it was chosen to represent each of the categories of the guidelines in Table 1 and to use web screens that are likely to be encountered by any user to ensure ecological validity (e.g. portal websites, websites with large amounts of text, or websites with pictures). Participants were asked to choose the version of the website they considered most pleasant to work with.

In addition to the web design items, the questionnaire included items on demographic status and internet usage. Demographic questions included date of birth, sex, level of education, and level of occupational activity. Level of education was measured with a Dutch scoring system $^{25}$ consisting of an 8-point scale, ranging from primary education to university education. Participants' professions were given 4 -digit $\operatorname{codes}^{26}$ which were subsequently transformed to the 7point level of occupational activity (LOA) score. This LOA score is based on a functional classification ${ }^{27}$ and ranges from low skilled to academic labour. The questions about internet use included the number of years participants had used the internet and the frequency of use (hours per week). Participants could indicate for which purposes they used internet.

Both the on-screen web design items and the questionnaire web design items focused on one of five dimensions of web design. The first dimension was 'text'. Two on-screen items were included to measure preferences with respect to font size and font type. For the first item, a portal-like website consisting of links to other websites on a similar topic was shown with several font sizes, ranging from 8 to 16 points. Font type (serif and sans serif) was varied on a website which contained a large amount of text. In the questionnaire, participants were asked which text justification they preferred (left, centered or right).

The second dimension was 'visibility'. A website containing general information on an academic course was used to present different text/background contrasts (positive -black letters on a white background- or negative -white letters on a black background-) and different letter contrasts (four versions ranging from light grey letters on a white background to black letters on a white background). Using the same website, four background-related web design features were manipulated. First, participants were asked if they preferred the presence of a photo or a logo in the background to a blank background, or vice 
versa. Next, preferences to different background contrast characteristics were measured, namely contrast and blur level. The former feature was manipulated using a background photograph of a class of students, of which the opacity ranged from 20 to 80 percent in four steps. The latter feature was varied by applying four different blur levels to the same background photograph.

The third dimension of web design was labelled 'visual clutter', referring to the amount of information on a website. One on-screen item showed a newspaper homepage, once with moving pictures (as present on the original website), once with non-moving pictures and once without pictures. Three related questionnaire items were included to ask participants about their preferences of using (non-)moving pictures in general and their preferences to information that is presented in a well-thought, usable way (with consideration of the abilities of the user).

The fourth dimension was labelled 'navigation'. An on-screen item showed a simple search engine website (Google) with several versions of a toolbar (text only, icons only, both text and icons). Four further questions in the questionnaire were included to ask participants which type of link they preferred (text, icon, or both), whether they preferred text-type hyperlinks placed within the main text of a website or placed in a separate column next to the main text, which location of separately placed hyperlinks they preferred (left, right, bottom, or top) and how pleasant they rated the use of roll-over effects (5-point Likert scale, ranging from very unpleasant to very pleasant).

The final web design dimension that was studied was called 'orientation'. For this dimension, three questionnaire items were used. First, participants were asked if they found the use of orientation cues to indicate one's location in the structure of the website pleasant or unpleasant (5-point scale). Next, they were asked to indicate which type of orientation cues they preferred (tabs, menus or links that change when one is on the corresponding page). Finally, participants were asked to rate the pleasantness of the use of frames or sub windows (5-point Likert scale ranging from very unpleasant to very pleasant).

\section{Procedure}

Participants were informed about the purpose of the study. After a brief instruction, they were seated in front of the laptop to view the versions of the websites. Each new website was introduced briefly on screen to direct participants' attention to the design characteristic of interest which was altered between the different versions of the website. After this, the different design versions of a typical website were subsequently presented with intervals of 3 seconds between the versions. Next, participants were allowed to leaf through the versions by themselves, at their own pace. All participants were instructed to judge the versions of the websites according to subjective usability, that is, they were specifically asked to indicate which of the versions they considered most pleasant to work with. After ticking off the preferred choice on a score form, the next web design characteristic was introduced. After all website versions had been presented and scored, participants were asked to fill out the questionnaire.

\section{Statistical Analyses}

ANOVAs were conducted to determine whether the age groups differed with regard to level of education, years of internet experience, and frequency of internet use. $\chi^{2}$-tests were used to analyse differences between the age groups in terms of sex and types of internet activ- 
ities reported. Both ANOVAs and $\chi^{2}$ tests were conducted to analyse preferences regarding web design features (both on-screen and questionnaire items). If the ANOVA showed a significant effect, Tukey post-hoc tests were done to make pair-wise comparisons between all age groups.

\section{RESULTS \\ Group Comparisons}

The demographic characteristics of each age group are presented in Table 2 . The groups did not differ in terms of level of education and occupation, but did in sex composition: unlike age groups 1, 2 and 3 , age group 4 consisted mainly of men (12 men vs. 2 women).

\section{Internet Activities}

Means for internet experience, frequency of internet use and number of internet activities are shown in Table 3 . The four groups did not differ with respect to experience, frequency, and the number of internet activities. The internet activities were further dichotomized ('used' or 'not used'), to analyze them separately, to study whether the choice of particular activities differed between the age groups. A significant effect was found for only one of the eleven activitvariables per age group ies: chatting $\left(\chi^{2}(3, \mathrm{~N}=107)=9.59, \mathrm{p}=\right.$ $0.02)$. The number of participants who used the internet for chatting decreased steadily with age: from $29.4 \%$ in group 1 to $0 \%$ in group 4 .

\section{Web Design Preferences}

Different aspects of web design were analyzed to investigate the effect of age on participants' preferences (Table 4).

\section{On-screen items}

There were significant differences between the age groups for the two fontrelated aspects, font size and font type. The participants in groups 3 and 4 preferred larger fonts (mean preferred font sizes were 12.8 and 13.4 points, respectively) than the participants in group 1 ( $p=0.04$ and $p=0.01$, mean preferred font size was 11.4 points) (Figure 1). The differences in font type were less straightforward (Figure 2). Most participants in groups 1 and 3 preferred a sans serif font type, while most participants in group 2 and 4 preferred a serif font type.

The age groups also differed significantly in their preference for pictures, no pictures, or moving pictures on a website (Figure 3). Participants in groups 1

Table 2. Means (M) and standard deviation in parentheses (SD) of some demographic

\begin{tabular}{l|lllll}
\hline $\begin{array}{l}\text { Group } \\
\text { (Age ranges) }\end{array}$ & $\mathbf{N}$ & $\begin{array}{l}\text { Age } \\
\text { (M, SD) }\end{array}$ & $\begin{array}{l}\text { Sex } \\
\text { (m/f ratio in \%) }\end{array}$ & $\begin{array}{l}\text { Education } \\
\text { (range 1-8) }\end{array}$ & $\begin{array}{l}\text { Occupation } \\
\text { (range 0-7) }\end{array}$ \\
\hline $1(19-34)$ & 34 & $26.2(4.3)$ & $44 / 56$ & $5.8(1.1)$ & $4.4(1.5)$ \\
$2(35-49)$ & 30 & $42.3(4.4)$ & $47 / 53$ & $5.8(1.1)$ & $5.0(1.5)$ \\
$3(50-64)$ & 29 & $57.1(4.0)$ & $59 / 41$ & $5.5(1.4)$ & $4.8(1.4)$ \\
$4(65-78)$ & 14 & $68.9(4.4)$ & $86 / 14$ & $5.5(1.7)$ & $5.3(1.5)$ \\
\hline
\end{tabular}

Table 3. Participants' use of internet per age group; for experience, frequency and activities means and standard deviations are presented

\begin{tabular}{l|lll}
\hline $\begin{array}{l}\text { Group } \\
\text { (Age ranges) }\end{array}$ & $\begin{array}{l}\text { Experience } \\
\text { (years) }\end{array}$ & $\begin{array}{l}\text { Frequency } \\
\text { (number / week) }\end{array}$ & $\begin{array}{l}\text { Activities } \\
\text { (total number) }\end{array}$ \\
\hline $1(19-34)$ & $6.7(2.9)$ & $7.3(6.4)$ & $4.3(1.9)$ \\
$2(35-49)$ & $5.9(3.1)$ & $10.8(13.0)$ & $4.5(2.2)$ \\
$3(50-64)$ & $5.2(3.5)$ & $7.3(11.2)$ & $3.2(2.1)$ \\
$4(65-78)$ & $5.8(4.7)$ & $4.5(5.9)$ & $3.8(1.6)$ \\
\hline
\end{tabular}


and 2 preferred the website version with non-moving pictures, whereas participants in groups 3 and 4 preferred versions with no pictures.

They also differed in their preference for a blank or a photo background to a website. About half of the participants in groups 1 and 2 preferred a photo background $(58.8 \%$ and $50.0 \%$ respectively), whereas about $80 \%$ of the participants in groups 3 and $4(86.2 \%$ and
$78.6 \%$, respectively) preferred a blank background (Figure 4). If a photo background was used, there were differences in the preferences for contrast and blur of the background (Figures $5 \&$ 6). Post-hoc analyses revealed that the participants in group 3 preferred a photo with lower contrast compared with participants in group $1(p=0.02)$. Also, participants in group 3 preferred a higher blur level of the photo background, that is, a less sharp photo, than

Table 4. Statistical analyses of group differences for the on-screen and questionnaire items on web design; For ordinal variables, ANOVAs were conducted, and means, standard deviations and F-values are given; For nominal variables, $\chi^{2}$-tests were done, and the $\chi^{2}$-values are given with degrees of freedom (df); " $p<.05 ; "{ }^{* *} p<.01$

\begin{tabular}{l|lllc}
\hline Aspect of web design & Preference & $\begin{array}{l}\mathbf{F} \\
(3,124)\end{array}$ & $\begin{array}{l}\chi^{2} \\
(\mathbf{d f}, \mathbf{N})\end{array}$ & Significance \\
\hline Text & & & & \\
Font size (8-16) & $12.15(2.18)$ & 4.66 & & $* *$ \\
$\begin{array}{l}\text { Font type (sans serif / serif) } \\
\text { Alignment (left, centred, right, no }\end{array}$ & $52 / 48$ & & $(3,107) 8.19$ & $*$ \\
preference) & $67 / 9 / 4 / 20$ & & $(9,107) 12.53$ &
\end{tabular}

\section{Visibility}

Text/background contrast (positive/negative)

Letter contrast (low - high 1-4)

Background contrast (low - high 1-4)

Background sharpness (low - high 1-4)

Photo background (blank/photo)

Logo background (blank/logo)

\section{Visual clutter}

Presence of pictures (unpleasant -

pleasant 1-5)

Presence of pictures (pictures, no pictures, moving pictures)

Presence of moving pictures (unpleasant pleasant 1-5)

Well-designed presentation of information (unpleasant - pleasant 1-5)

\section{Navigation}

Type of toolbar (text/icons/both)

Type of links (text/icon/no preference)

Links in text (in text/outside text/no

preference)

Location of link (left/right/bottom/top/no preference)

Use of roll-over (unpleasant - pleasant 1-5)

\section{Orientation}

Use of orientation cues (unpleasant -

pleasant 1-5)

Type of cues (tab/menu/changing link/ no preference)

Use of frames/sub windows (unpleasant -

pleasant 1-5)
$73 / 27$

$(3,106) 3.11$

$\begin{array}{lll}3.92(.28) & 1.83 & \\ 1.44(.69) & 3.06 & \\ 2.92(1.25) & 4.55 & \\ 61 / 39 & & (3,107) 16.66 \\ 78 / 22 & & (3,107) 6.49\end{array}$

$3.32(1.00)$

4.76

$41 / 39 / 20$

$(6,107) 19.50$

$2.19(1.13)$

1.32

$4.51(.84)$

.69

$15 / 16 / 69$

$60 / 12 / 28$

$43 / 32 . / 25$

$(6,107) 4.59$

$(6,107) 3.34$

$(6,106) 1.62$

$70 / 4 / 4 / 4 / 18$

$(12,106) 7.53$
2.49

$4.18(1.03) \quad .53$

$19 / 57 / 11 / 13$

$(9,106) 6.12$

$3.30(1.10)$ .52 


\section{User preferences for web design}

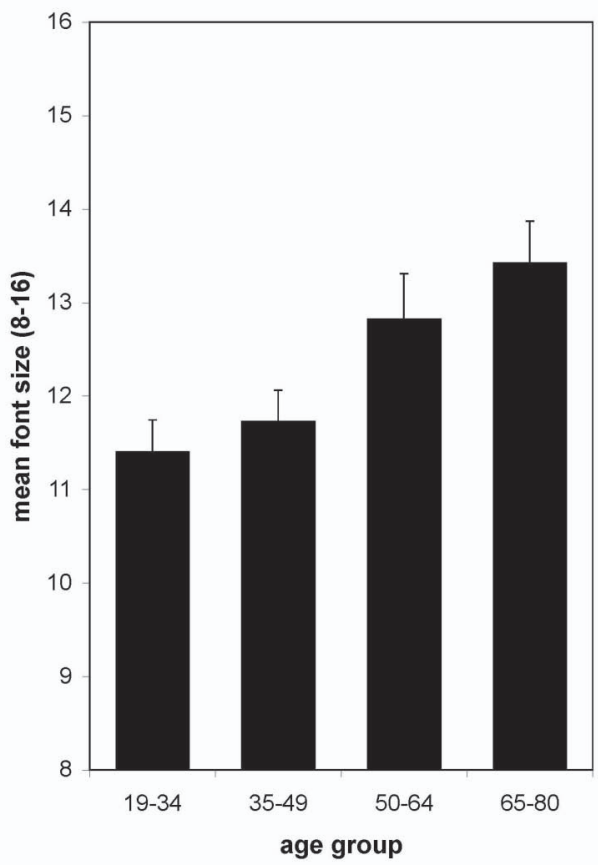

Figure 1. Mean (SE) preferences to font

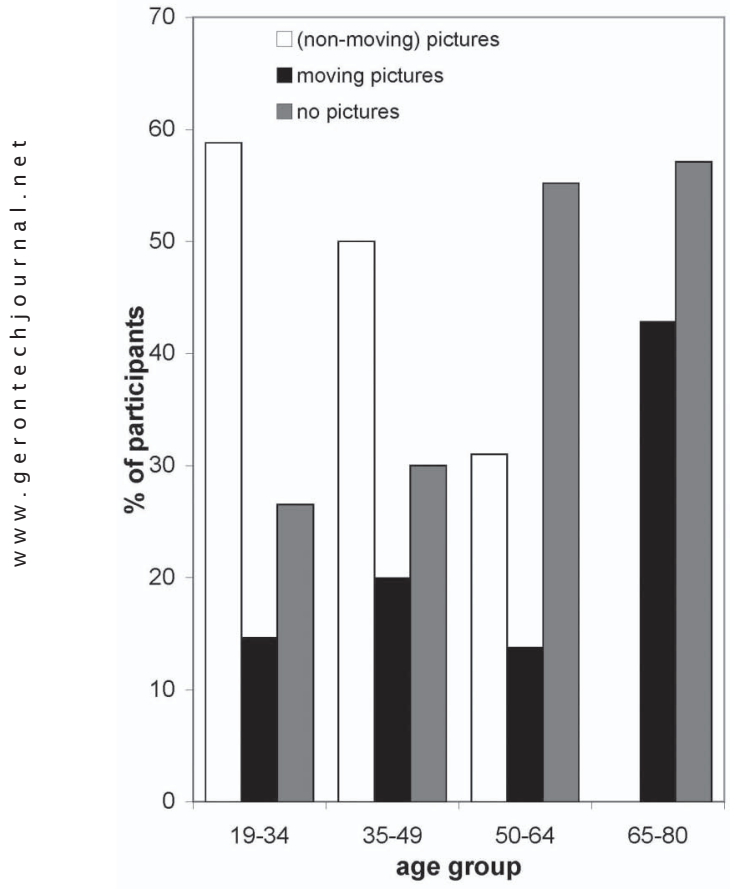

Figure 3. Preferences to (non-moving) pictures, moving pictures or no pictures

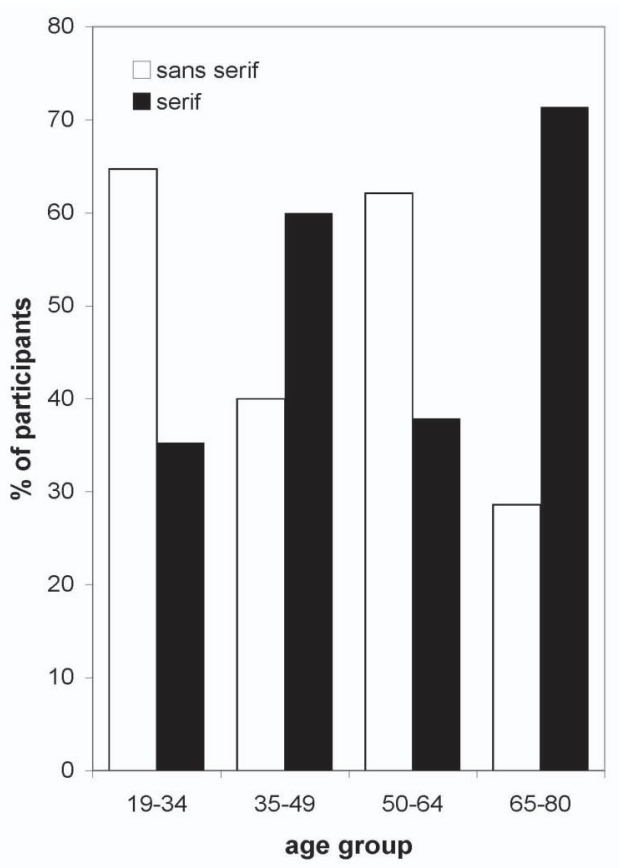

Figure 2. Preferences to font types

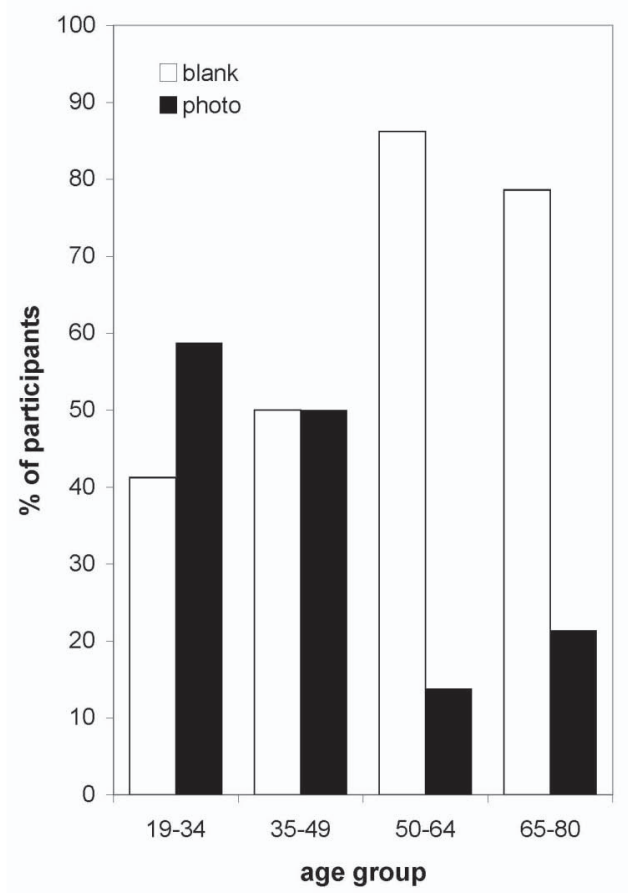

Figure 4. Preferences to a blank background versus a photo background 


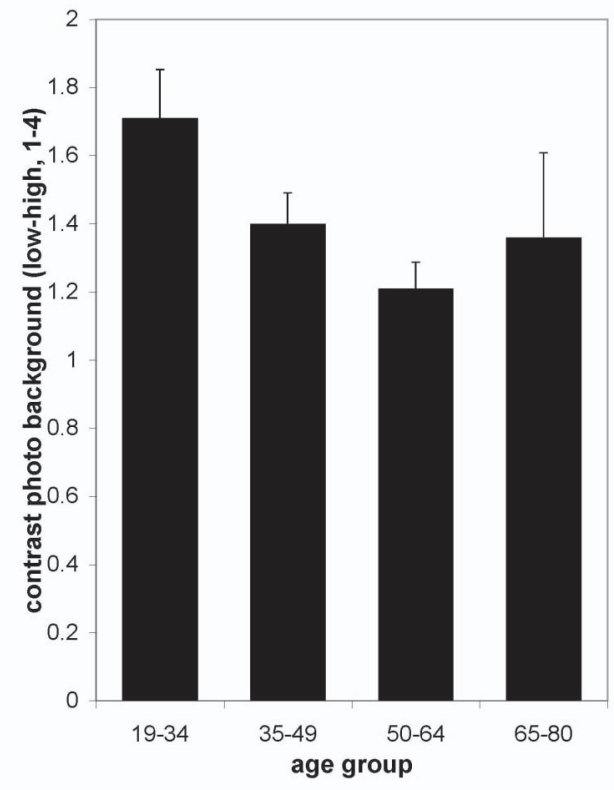

Figure 5. Mean (SE) preferences to the contrast of a photo background

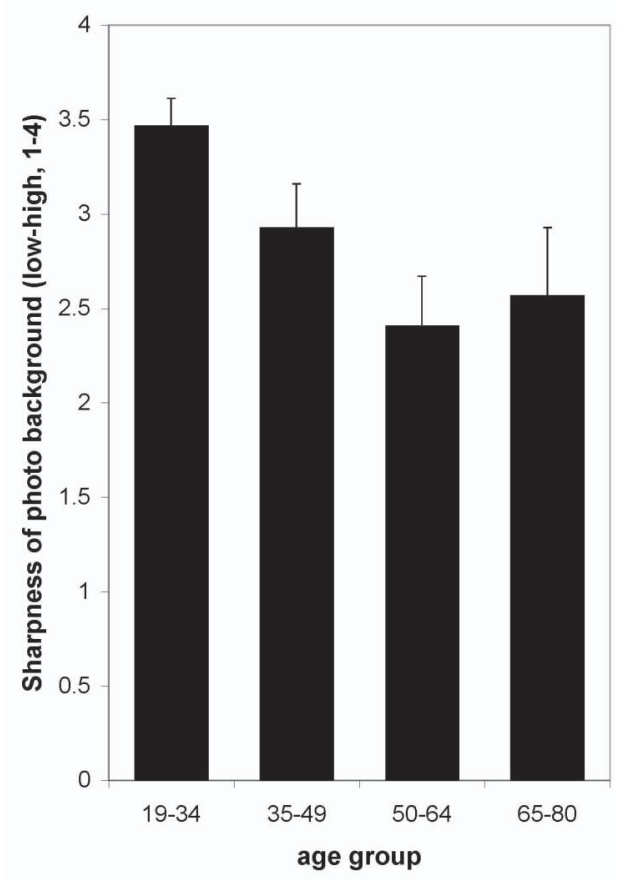

Figure 6. Mean (SE) preferences to the sharpness (blur level) of a photo background the participants in group $1(\mathrm{p}<0.01)$.

\section{Questionnaire items}

The questionnaire indicated a significant difference between age groups with respect to the presence of (non-moving) pictures (Table 4). Post-hoc analysis showed that the participants in age groups $3(p=0.02)$ and $4(p=0.05)$ found the presence of pictures less pleasant than did the participants in age group 1 (Figure 7), which is in line with the results of the on-screen 'presence of pictures' item. No differences between age groups were found for the presence of moving pictures. However, t-tests, which compared these two items, showed that the participants in groups 1,2 , and 3 found moving pictures less pleasant than non-moving pictures $(\mathrm{t}(33)=9.10, \mathrm{p}<0.01$ for group $1, \mathrm{t}(29)$ $=6.28, \mathrm{p}<0.01$ for group $2, \mathrm{t}(28)=$ $5.13, p<0.01$ for group 3 and $t(13)=$ $2,10, p=0,06$ for group 4) (Figure 8).

\section{Discussion}

The aim of this study was to compare the preferences for web design features of older and younger web users and to identify any discrepancies between these preferences and existing guidelines for interface design. Overall, the preferences of older and younger users corresponded quite well - an effect of age was found on three aspects of web design, namely, font (both type and size), the use of a photo as background (a photo background compared with a blank background and with regard to the contrast and level of blur of the photo), and the presence of (nonmoving) pictures. As has been argued above, one of these differences may be mediated by age-related functional decline. Older participants preferred larger font sizes, possibly due to reduced eyesight. The differences between the age groups with respect to font type are more difficult to interpret because the age effects were less meaningful. The 


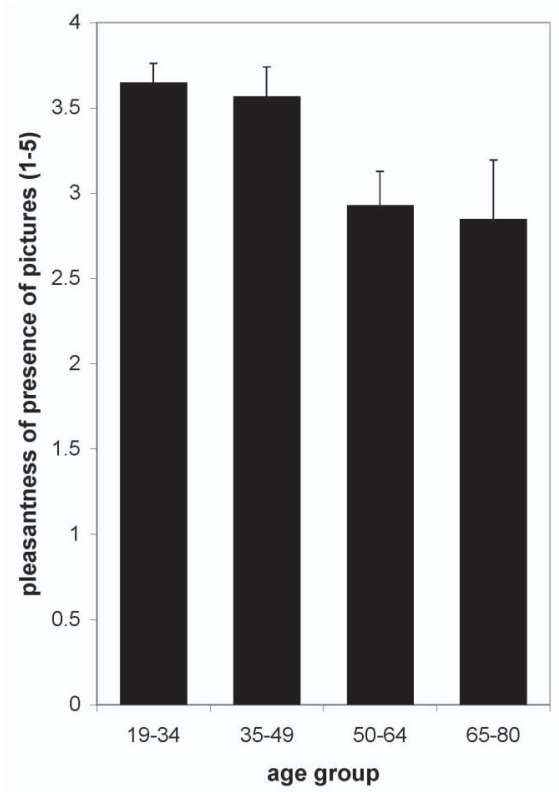

Figure 7. Mean (SE) preferences to the use of (non-moving) pictures

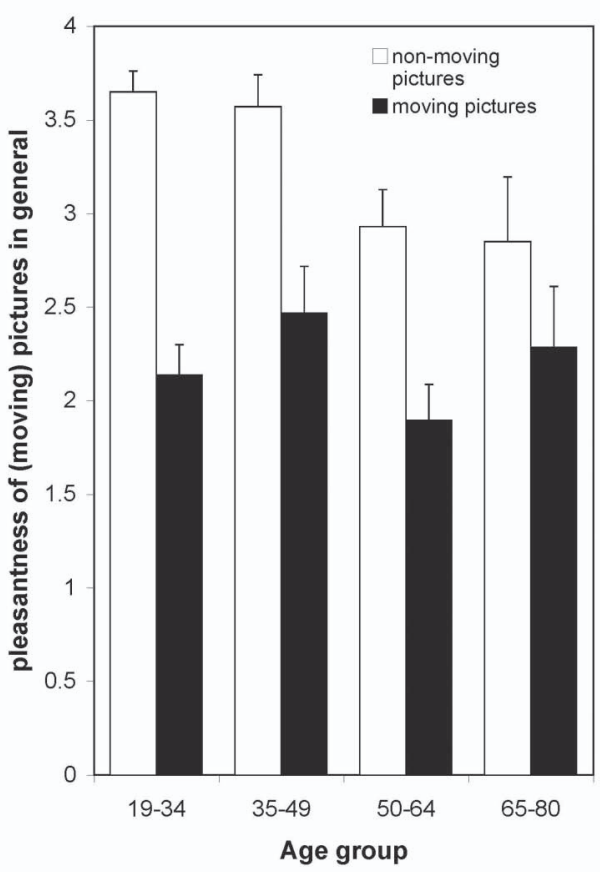

Figure 8. Mean (SE) preferences to both the use of moving and non-moving pictures results regarding font size and font type partly correspond to the results reported by Bernard et al. ${ }^{23}$, which were described above. We found a preference for the similar font type (14 points) as recommended by Bernard et al. On the other hand, participants in their study preferred a sans serif font type, where 60 percent of our oldest participants preferred a serif font type. The difference in preferences between younger and older computer users with respect to font size was not very large (2 points), but apparently, older adults tend to be more satisfied with websites with a font size of 14 points than a font size of 12 points.

Next, older adults preferred a blank background (instead of a photo background) whereas the younger participants (groups 1 and 2) had a less pronounced preference on this point. Older adults may find it harder to extract relevant information from the screen and may find irrelevant information on a website, including a patterned background, more distracting. The same holds for the presence of (non-moving) pictures, which younger users preferred more than older users did. With respect to the contrast and level of blur of a photo used as background, the middleaged participants (group 3; 50 to 64 years of age) preferred a lower contrast and higher level of blur. This can be related to differences in contrast sensitivity, i.e. foreground/background discrimination, which steadily declines with age $^{28}$. Surprisingly, the age differences for both items were found only for the participants of group 3 but not for the participants of group 4. A possible explanation for this may be a cohort effect, as participants in the oldest age group were probably the only participants in this study who had not been introduced to computers in a school or work situation. Instead, most of these people started to use the internet com- 
pletely out of their own interest and motivation. These participants probably were high functioning older adults and might not be fully representative of average older adults.

Overall, there appeared to be few differences in web design preferences between older and younger users. This favours the universal design approach, which assumes that design principles aimed at accommodation of the older user should also be beneficial to younger users. We found no evidence to suggest that younger users might not appreciate interfaces that meet these principles.

We compared our user preferences with current interface guidelines (Table 1). Most of these guidelines were consistent with the participants' preferences, but some differences were found. We did not find a clear preference for sans serif font types, which are recommended in several guidelines, $6,148-20$. Also, Echt $^{19}$ recommended minimizing the number of hyperlinks within text, whereas most of our participants preferred links to be embedded in the text rather than outside the text. We also have not found a preference for the use of icons as hyperlinks and the use of walking menus, as was recommended by Echt ${ }^{19}$ and Holt $\&$ Morrell $^{14}$. Most of our participants preferred text to icons as hyperlinks and the use of walking menus as an orientation cue to the use of tabs or changing links. These differences between guidelines and user preferences suggest that people's preferences are not entirely based on their functional capabilities, while other factors, such as aesthetics, may also play a role. When designing a web interface therefore, we suggest to not only take users' capabilities into account, but also to ask potential users about their preferences. When these preferences contradict the performance measures, it should be con- sidered to prioritize the preferences, as these may render a website more attractive to the users. When solely focusing on users' capabilities, one may make sure that the user can easily navigate the website. However, usability does not only concern the effectivity and efficiency of use, it is also defined by the user's satisfaction ${ }^{29}$. Hence, to perceive a website as a useful one, ideally the user should be satisfied about all aspects of the website.

Based on the results of the present study, it is not possible to decide conclusively what exactly influences users' preferences to the design of web interfaces. The preferences may not only be affected by cognitive abilities, but may also be determined by factors such as aesthetics. To be able to establish decisively the effect of age-related cognitive decline on older users' web performance, more research in larger groups of individuals is necessary. As measures of physical limitations and performance were not taken in this study we cannot draw definite conclusions about the actual relation between user preferences and capabilities. Still, this study is the first to show that user preferences need to be taken into account next to capacity-based considerations.

Another issue that is associated to the relationship between the existing guidelines and the user preferences found in the present study concerns the study material. As was discussed earlier, the existing guidelines were not based on empirical findings by manipulating actual interfaces to test user performance. These guidelines are based on commonly observed age-related declines in vision, perception, cognition and motor skills. This implies that the guidelines may be used for very different types of websites, where we have only manipulated the design aspects in one typical, but specific web design. 
Therefore, it may be possible that the type of website and the task (for instance, reading, searching for information) affect the preferences of the user with respect to the guidelines. Therefore, the present results can only be interpreted within the context of the material that was used. For the websites that were used in the present study, we are able to conclude that user preferences do not entirely match to the general design guidelines, which demonstrates the importance of taking user preferences into account as well.

The four age groups were similar in terms of both quantitative (experience in years and frequency of use) and qualitative (the types of internet activities) aspects of internet use. A possible limitation of our study is that the oldest group (group 4) was substantially smaller and had a different male/female composition than the other three age groups. These differences, however, do reflect the actual difference in age distribution of internet users. For example, a recent survey of information technology use in the Dutch population ${ }^{30}$ revealed that fewer people in the oldest group (65 years and older) than in younger groups are connected to internet (17\% versus $50 \%-73 \%$ ), which in part explains the difficulty of recruitment of participants in the oldest category. As for the different male/female ratio in the oldest age group, we only found one significant difference between male and female participants, namely in the total study population female participants preferred hyperlinks located outside the mail text of a website and male participants preferred hyperlinks to be located in the text. That is, in general there were no significant differences between preferences for web design of male and female internet users. Therefore, we do not expect such differences in the oldest age group either.
In summary, we found few age-related differences in user preferences for web design features. Although most preferences matched ability-based guidelines, some differences were apparent, suggesting that users sometimes prefer versions of websites that may not optimally meet their perceptual, motor, or cognitive abilities. Therefore, when developing new guidelines and new websites or interfaces, designers should try to incorporate both user preferences as well as user functional abilities.

\section{Acknowledgements}

The authors acknowledge Lennard Kuijten and Salmon Schiffer for assistance with the data collection and data entry.

\section{References}

1. Czaja SJ. Aging and the acquisition of computer skills. In: Walker N, editor. Aging and skilled performance: Advances in theory and applications. Mahwah: Lawrence Erlbaum; 1996; pp 201-220

2. Mead SE, Batsakes P, Fisk AD, Mykityshyn A. Application of cognitive theory to training and design solutions for age-related computer use. International Journal of Behavioral Development 23(3):553-573;1999

3. Morrell RW, Mayhorn CB, Bennett J. A survey of World Wide Web use in middle-aged older adults. Human Factors 42(2):175-182; 2000

4. Morrell RW. Older adults, health information, and the World Wide Web. Mahwah: Erlbaum; 2002

5. Cody MJ, Dunn D, Hoppin S, Wendt P. Silver surfers: Training and evaluating internet use among older adult learners. Communication Education 48:269-286;1999

6. Czaja SJ, Lee CC. Designing computer systems for older adults. In: Jacko J,Sears A, editors. The human-computer interaction handbook. Mahwah: Lawrence Erlbaum; 2003; pp 413 427

7. Czaja SJ, Guerrier JH, Nair SN, Landauer TK. Computer communication as an aid to independence for older adults. Behaviour \& Information Technology 12(4):197-207;1993 
8. Czaja SJ, Sharit J. The influence of age and experience on the performance of a data entry task. Paper presented at the Human factors and ergonomics society $41^{\text {st }}$ annual meeting, Albuquerque; 1997

9. Kelley CL, Charness N. Issues in training older adults to use computers. Behaviour and Information Technology 14(2):107-120;1995

10. Mead SE, Spaulding VA, Sit R A, Meyer B, Walker N. Effects of age and training on World Wide Web navigation strategies. Paper presented at the Human factors and ergonomics society $41^{\text {st }}$ annual meeting, Albuquerque; 1997

11. Mead SE, Jamieson BA, Rousseau GK, Sit RA, Rogers WA. Online library catalogs: Age-related differences in query construction and error recovery. Paper presented at the Human factors and ergonomics society $40^{\text {th }}$ annual meeting, Philadelphia; 1996

12. Walker N, Millians J, Worden A. Mouse accelerations and performance of older computer users. Paper presented at the Human factors and ergonomics society $40^{\text {th }}$ annual meeting, Philadelphia; 1996

13. Rogers WA, Fisk AD. Human factors, applied cognition and aging. In: Salthouse TA, editor. The handbook of aging and cognition. Mahwah: Lawrence Erlbaum; 2000; pp 559-591

14. Holt BJ, Morrell RW. Guidelines for Web site design for older adults: The ultimate influence of cognitive factors. In: Morrell RW, editor. Older adults, health information and the World Wide Web. Mahwah: Lawrence Erlbaum; 2002; pp 109-129.

15. Gerven PWM van, Paas FGWC, Merrienboer JJG van, Schmidt HG. Cognitive load theory and the acquisition of complex cognitive skills in the elderly: Towards an integrative framework. Educational Gerontology 26:503-521;2000

16. Fleming J. Web navigation: Designing the user experience. Sebastopol, CA: O'Reilly; 1998

17. Nielsen J. Designing web usability: The practice of simplicity. Indianapolis: New Riders; 1999

18. Mead SE, Lamson N, Rogers WA. Human factors guidelines for Web site usability: Health-oriented Web sites for older adults. In: Morrell RW, editor. Older adults, health information, and the World Wide Web. Mahwah: Lawrence Erlbaum; 2002; pp 89-107.
19. Echt KV. Designing Web-based health information for older adults: Visual considerations and design directives. In: Morrell RW, editor. Older adults, health information, and the World Wide Web. Mahwah: Lawrence Erlbaum; 2002; pp 61-87.

20. Laux LF. Aging, communication, and interface design. In: Charness N, Parks DC, Sabel BA, editors. Communication, technology and aging. New York: Springer; 2001; pp 153-168

21. Craik FIM, Salthouse TA. The handbook of aging and cognition. Mahwah: Lawrence Erlbaum; 2000

22. Schaie KW. The course of adult intellectual development. American Psychologist 49(4):304313;1994

23. Bernard M, Liao C, Mills M. Determining the best online font for older adults. Usability News 3(1);2001 http://psychology.wichita.edu/surl/usabilitynews/3W/fontSR.htm; Accessed June 10, 2005

24. Story MF, Mueller JL, Mace RL. The universal design file: Designing for people of all ages and abilities. Raleigh: North Carolina State University, The Center for Universal Design; 1998

25. Bie SE de. Standaardvragen 1987: Voorstellen voor uniformering van vraagstellingen naar achtergrondkenmerken en interviews (in Dutch) [Standard questions 1987: Proposal for uniformization of questions regarding background variables and interviews]. Leiden: Leiden University Press; 1987

26. CBS. Beroepenclassificatie 1984 (in Dutch) [Classification of Occupations 1984]. Voorburg: Centraal Bureau voor de Statistiek; 1985

27. Brand PA van den, Goldbohm RA, Veer P van 't, Volovics A, Hermus RJ, Sturmans F. A largescale prospective cohort study on diet and cancer in the Netherlands. Journal of Clinical Epidemiology 43:285-295;1990

28. Boxtel MPJ van, Tusscher MPM ten, Metsemakers JFM, Willems B, Jolles J. Visual determinants of reduced performance on the Stroop Color-Word Test in normal aging individuals. Journal of Clinical and Experimental Neuropsychology 23(5):620-627; 2001

29. ISO. ISO 9241-11: Guidelines for specifying and measuring usability. ISO; 1998

30. Haan J de, Steyaart J. Jaarboek ICT en samenleving. Den Haag: SCP; 2003 